\title{
ANÁLISE COMPARATIVA DE INDICADORES MORFOMÉTRICOS DA BACIA DO RIO VAZA BARRIS E DO RIO MACURURÉ COMO SUBSÍDIO A IDENTIFICAÇÃO DE ÁREAS SUCEPTÍVEIS A DESERTIFICAÇÃO NO POLO DE JEREMOABO / BA
}

\author{
Sande Oliveira Santos ${ }^{1}$; Jocimara Britto Lobão ${ }^{2}$ e Aislan Santana Carneiro ${ }^{3}$ \\ 1. Bolsista PIBIC/CNPq, Graduando em Licenciatura em Geografia, Universidade Estadual de Feira de Santana, e-mail: \\ sandeoliveira@live.com \\ 2. Orientadora, DCHF, Universidade Estadual de Feira de Santana, e-mail: juci.lobao@gmail.com \\ 3. Participante do projeto Análise ambiental no semiárido baiano como subsídio ao ordenamento territorial: a vulnerabilidade \\ à desertificação no Polo de, DCHF, Universidade Estadual de Feira de Santana, e-mail: aislan.carneiros@ gmail.com
}

PALAVRAS-CHAVE: Bacia Hidrográfica Intermitente; Análise Morfométrica; Geoprocessamento.

\section{INTRODUÇÃO}

Este trabalho está balizado no estudo sistêmico da bacia hidrográfica do rio Vaza Barris. Para melhor discutir os o tema em questão optou-se por realizar um trabalho fundamentado numa abordagem geográfica sistêmica comparativa das bacias hidrográficas do Rio Vaza Barris e do Rio Macururé, localizadas na região nordeste da Bahia, no Polo de Jeremoabo. Tendo como objetivo principal uma análise morfométricas, deve-se ter em conta que a morfometria de uma bacia hidrográfica é um dos artifícios feitos em análises hidrográficas ou ambientais. Segundo Antonelli e Thomaz (2007), a combinação dos diversos dados morfométricos permite diferenciar áreas homogêneas. Estes parâmetros revelam indicadores físicos específicos para um local, qualificando as alterações ambientais. Desta forma realizou-se um estudo sistêmico da bacia do Vaza Barris, enfocando os indicadores morfométricos que mais se relacionam com a desertificação, e comparou-se com alguns parâmetros morfométricos da bacia do rio Macururé. Este trabalho é de extrema relevância, pois possibilita, ao gerar dados, a identificação e o mapeamento de áreas propícias à desertificação em bacias hidrográficas em ambientes semiáridos. Vale salientar também a importância da Ciência Geográfica no que diz respeito ao entendimento da dinâmica ambiental, e das relações que esta tem com as práticas antrópicas, realizando, assim, estudos de integração, contemplando a interação entre os sistemas naturais e humanos. Os estudos geográficos constituem um dos artifícios mais eficientes e necessários para o estabelecimento de indicadores biofísicos e socioeconômicos concernentes ao fenômeno em estudo.

\section{METODOLOGIA}

A análise morfométrica visou detalhar e revelar a morfologia fluvial da bacia hidrográfica do rio Vaza Barris, por meio dos resultados dos cálculos dos seguintes parâmetros: Área; Perímetro; Altimetria; Declividade; Curvas de nível; Índice de compacidade; Hierarquia dos canais de drenagem; Comprimento do rio principal; Comprimento total da rede hídrica; Forma da sub-bacia; Número total dos canais de drenagem; Densidade de drenagem; Densidade hidrográfica; Coeficiente de manutenção; Dissecação vertical; Dissecação horizontal. Todavia, não são simplesmente os cálculos que forneceram os resultados almejados, mas um conjunto de elementos integrados que permitiram a caracterização da bacia, as variáveis ambientais (clima, vegetação, relevo, solos e geologia) e a geomorfologia fluvial da bacia em estudo.

Realizou-se, a princípio, o levantamento bibliográfico concernente aos temas aqui discutidos. Em paralelo foi realizada uma caracterização geral e análise de forma integrada os diferentes elementos físicos que contribuem para a construção da paisagem da bacia e seu entorno. Posteriormente, foi feita a delimitação da área da bacia, com sabe em técnicas de geoprocessamento, por meio de imagens Shuttle Radar Topography Mission (SRTM), e de 
Modelo Digital de Terreno (MDT). O MDT serviu também para fazer os cálculos das variáveis morfométricas. Foi possível cruzar e manipular dados geograficamente georreferenciados para construir um banco de dados, um Sistema de Informação Geográfica (SIG). Por meio deste foi possível elaborar mapas temáticos diversos que deram suporte para a análise dos resultados por meio de mapas, quadros-síntese, etc. Para concluir foi realizado uma comparação discursiva entre os parâmetros morfométricos calculados para as bacias dos rios Macururé e Vaza Barris.

\section{RESULTADOS E DISCUSSÃO}

Por se tratar se uma bacia hidrográfica situada num clima semiárido, com secas prolongadas e irregularidades pluviométricas, além de possuir aspectos geomorfológicos baixos e medianos, devido a interferência climática, bem como estar locada numa área propícia aos processos de desertificação, foi significante estudar alguns parâmetros morfométricos na bacia do rio Vaza Barris pelo fato desta ser mais úmida que a bacia do rio Macururé, a fim de compará-las.

A forma da bacia é outro dado muito relevante, pois ela tem influência sobre o comportamento hidrológico da bacia. Sobretudo no que trata do tempo de concentração que é o tempo necessário, desde o início das precipitações, para que toda a bacia contribua com a vazão (CHRISTOFOLETTI 1980).

Dessa maneira, primeiramente, foi delimitada a bacia. Posteriormente constatou-se que a forma geométrica mais próxima da bacia do rio Vaza Barris é a retangular, e esta possibilita maiores processos de escoamento hídrico do que de acumulação de água numa forma arredondada. Também é retangular a forma da sub-bacia do rio Macururé. No que tange as questões de forma, ambas possuem mesmas características. Diferindo em tamanho da área e do perímetro. Além da forma, outros parâmetros devem ser considerados para analisar uma bacia hidrográfica (quadro 01), dentre eles: área total, perímetro, densidade de drenagem, número de canais, etc.

Quadro 01 - Resultados das variáveis morfométricas para análise comparativa entre a bacia do rio Vaza Barris e a sub-bacia do rio Macururé

\begin{tabular}{|l|l|l|}
\hline PARÂMETROS & VAZA BARRIS & MACURURÉ* \\
\hline Área & $14.517 \mathrm{Km}^{2}$ & $4.392 \mathrm{Km}^{2}$ \\
\hline Perímetro & $855 \mathrm{Km}$ & $409 \mathrm{Km}$ \\
\hline X Coordenada Centro & $539,575413 \mathrm{Km}$ & $497,918974 \mathrm{Km}$ \\
\hline Y Coordenada Centro & $14.517,1 \mathrm{Km}$ & $8.969,4 \mathrm{Km}$ \\
\hline Cota Mínima & $65 \mathrm{~m}$ & $301 \mathrm{~m}$ \\
\hline Cota Máxima & $926 \mathrm{~m}$ & $734 \mathrm{~m}$ \\
\hline Índice De Compacidade & 1,99 & 1,742372 \\
\hline Comprimento Do Rio Principal & $450,6 \mathrm{Km}$ & $182,1 \mathrm{Km}$ \\
\hline Ordem Da Bacia & 7 & 5 \\
\hline Comprimento Da Rede Hídrica & $11.292,2 \mathrm{~km}$ & $3.421,4 \mathrm{Km}$ \\
\hline Forma Da Bacia & Retangular - alongada & Retangular - Alongada \\
\hline Número Total Dos Canais De Drenagem & 8.979 & 676 \\
\hline Densidade De Drenagem & $0,777 \mathrm{Km} / \mathrm{km}^{2}$ & $0,788 \mathrm{~km} / \mathrm{km}^{2}$ \\
\hline Densidade Hidrográfica & $0,61 \mathrm{Km} / \mathrm{km}^{2}$ & $0,61 \mathrm{~km} / \mathrm{km}^{2}$ \\
\hline Coeficiente De Manutenção & $1.287 \mathrm{~m} / \mathrm{m}$ & $1.269 \mathrm{~m} / \mathrm{m}$ \\
\hline
\end{tabular}

Elaboração: Sande Oliveira Santos, 2016 - * Dados do relatório de Carneiro, 2015

De acordo com o quadro 01 a área total da sub-bacia do rio Macururé corresponde a $4.392 \mathrm{Km}^{2}$, uma área relativamente grande quando comparada ao tamanho total do polo de Jeremoabo de $2.499 \mathrm{~km}^{2}$. A Bacia do rio Vaza Barris é cerca de 3 vezes maior, ela tem área total de 14.517 $\mathrm{Km}^{2}$. Seu território se estende da Bahia a Sergipe, saindo da área do polo.

O tamanho da área dessas duas unidades importa para discutir o Polo pois as características morfométricas delas estão ligadas as condições que levam a desertificação, dessa forma, o 
grande tamanho delas tem significância relativa aos estudos da desertificação, já que é dentro do polo que se encontram as áreas mais susceptíveis a este processo. Os processos erosivos para o tamanho destas áreas são acentuados, dando evidência a um maior grau de degradação das terras, e consequente brecha para a instalação dos processos de desertificação, principalmente nas áreas de baixo curso, porque a ação climática, a aridez excessiva e a atuação das atividades antrópicas, como pecuária extensiva, que nelas ocorrem, abem espaço para esta degradação ambiental.

O perímetro da sub-bacia do rio Macururé equivale a 409,4 Km, possuindo cotas altimétricas mínimas de 301 metros e máximas de 734 metros, respectivamente, podendo afirmar que tratase de uma sub-bacia de geomorfologia baixa, já que se encontra sobre pedimentos funcionais retocados pro drenagem incipiente e por tabuleiros. Quanto a Vaza Barris o perímetro chaga a $855 \mathrm{~km}$, tendo cota mínima de 65 e máxima de 926 metros. Geomorfologicamente apresenta características semelhantes a outra.

Conforme a análise dos resultados, pode-se afirmar que a drenagem do rio principal da bacia do rio Vaza Barris é quase três vezes maior que a do rio Macururé que tem 182,1 km de comprimento. Na sub-bacia do rio Macururé o curso superior tem altimetria de aproximadamente 700 metros, no Vaza Barris esse valor chega a pouco mais que 900 metros. Isto indica que no curso superior as declividades são mais acentuadas, podendo chegar a $38^{\circ}$ de inclinação, características típicas de alto curso, o que permite a ação da erosão acelerada e consequentemente o transporte de sedimentos grosseiros indo para as partes mais baixas que possibilita assoreamento dos cursos de rios mais a baixo. $\mathrm{O}$ baixo curso inicia quando o leito do rio apresenta 360 metros na Macururé e apenas 65 metros na Vaza Barris. No caso Macururé é possível perceber um intervalo de cerca de $340 \mathrm{~m}$. Criando uma relação entre o valor do curso superior e o de curso mínimo pode-se entender que a declividade diminui gradativamente, influenciando na deposição de alguns sedimentos. Todavia, bacia do Vaza Barris ocorre uma diferença maior entre a cota máxima e a mínima, o que permite inferir que a transição é mais abrupta. Contudo, deve-se levar em conta que esta é uma bacia maior que a outra. Também há que se considerar o fato de ela desaguar no oceano e que a faixa litorânea apresenta relevos mais baixos com declividades bem suaves. Portanto a transição entre a cota máxima e a cota mínima é gradativa. O número total de canais de drenagem, obtidos a partir de cálculos morfométricos, é de 676 canais de escoamento (Macururé), sendo que a maioria deles são de ordem hierárquica 1 e 2, e também pequenos. Muitos desses canais são considerados riachos e córregos, que alimentam o rio principal, o Macururé. Todos eles possuem características temporárias, ou seja, seu regime hídrico é intermitente. O comprimento total da rede de drenagem é de $3.421 \mathrm{Km}$, sendo que o rio principal possui $182 \mathrm{Km}$ de comprimento, maior do que a distância entre as cidades de Feira de Santana e Salvador (101 Km). O total de canais na Vaza Barris é de 8.979. O número grande de canais, comuns de bacias hidrográficas úmidas, pode levar a crer que esta área é bastante úmida, contudo, a maior parte desses canais são apenas áreas de escoamento que apenas existem enquanto há precipitações. Sendo eles na hierarquia de ordem de canais de $1^{\circ}$ a $3^{\circ}$ ordem que representam $86 \%$ do total de canais. Sendo que os de $1^{\circ}$ ordem somam $50 \%$ deles. Isso interfere diretamente na densidade de drenagem, uma vez que esta é dada pela relação da quantidade de canais e o tamanho da área. Em ambos os locais pesquisados aqui a densidade foi semelhante ficando em $0,777 \mathrm{~km} / \mathrm{km}^{2}$ e $0,788 \mathrm{~km} / \mathrm{km}^{2}$.

O Coeficiente de manutenção que concerne a área mínima necessária para a manutenção de um metro de canal de escoamento, $\mathrm{O}$ resultado encontrado para a bacia do rio Vaza Barris foi de aproximadamente $1.200 \mathrm{~m}^{2} / \mathrm{m}$ para ambos locais analisados. Isso revela que cada metro da bacia e da sub-bacia tem a disposição para manter-se. Sendo esta a área de recarga. Outro dado muito importante é o resultado do balaço hídrico do munícipio de Jeremoabo. Elaborado com capacidade de $125 \mathrm{~mm}$, demostra os problemas hídricos da região. O baixo volume de precipitação compromete a manutenção da bacia e por isso gera déficit em todos os meses do 
ano. Isso indica que este lugar apresenta grande déficit hídrico em todos os meses durante o período estudado. O resultado negativo para Jeremoabo implica dizer que esta é uma realidade da região e portanto para a bacia do Vaza Barris.

A principal diferença entre a bacia do rio Vaza Barris e a sub-bacia do rio Macururé é o tamanho. As duas estão inseridas no mesmo domínio morfoclimático e, portanto, ambas unidades estudadas apresentaram índices com resultados bem próximos. Contudo, o tamanho faz a bacia do rio Vaza Barris ser mais úmida que a outra, porém continua a ser semiárida. Pois, a forma alongada de ambas possibilita uma vazão maior, se estas fossem circulares os resultados seriam mais positivos. A escassez de chuvas durante a maior parte do anos que traz chuvas torrenciais no verão criam os escoamentos superficiais que amentaram o número de canais e de ordem. Eles são importantes elementos para a análise de uma bacia numa área seca, pois o seu surgimento durante o período chuvoso alimenta os cursos que alimentam o rio principal. Ao surgirem eles ocupam cerca de $5.769 \mathrm{~km}$ de pequenos córregos que carregam águas para os rios. A sua ocorrência é parte importante da dinâmica de uma região árida.

\section{CONSIDERAÇÕES FINAIS}

O presente trabalho apresentou resultados muito bons sobre a importância da morfometria de uma bacia em áreas semiáridas contribuindo com temática da desertificação e com isso criando a possibilidade de novas análises e trabalhos. Constata-se como a paisagem da bacia no polo se encontra em alto grau de degradação, devido a ineficiência de recarga hídrica dos canais de drenagem como diagnosticado com o baixo valor da variável de coeficiente de manutenção. Ainda que a densidade de drenagem tenha apresentado um índice alto e ordens de canais de até a $7^{\circ}$ ordem o coeficiente de manutenção, baixo, comprova que essa densidade é resultado de linhas de escoamento efêmeras e portanto, não contribuem para alimentar a bacia o ano todo, ainda que sejam importantes. A revisão de literatura foi essencial para identificar e escolher quais variáveis morfométricas de maior interesse para análise e discussão. As Geotecnologias foram eficientes ao produzir os resultados. Cada indicador mensurado e analisado neste trabalho tem uma participação no resultado final, na análise integrada da paisagem. Considerando isso deve-se ter em conta apenas um indicador sozinho não pode explicar um fenômeno ou uma realidade, dessa forma é necessário e indispensável utilizar diversos parâmetros, e portanto, para este trabalho utilizou-se um grande número de variáveis. Destarte, os resultados e análises deste trabalho demonstraram a sua importância, pois analisou parâmetros morfométricos da sub-bacia do Macururé, analisando a sua dinâmica e interação entre os elementos humanos e naturais. Além disso, deu continuidade ao projeto "Análise ambiental no semiárido baiano como subsídio ao ordenamento territorial: a vulnerabilidade à desertificação no polo de Jeremoabo", contribuindo para a geração de estudos geoambientais que viabilizem um planejamento e ordenamento territorial coerente e eficiente, levando em conta as características particulares da área estudada.

\section{REFERÊNCIAS}

ANTONELI, V; THOMAZ, E.L. Caracterização do meio físico da bacia do Arroio Boa Vista, Guamiranga-PR. Rev. Caminhos da Geografia, Uberlândia, v.8, n.21, p46-58, jun. 2007.

CARNEIRO, Aislan Santana. Avaliação sazonal/anual (2001 a 2011) da biomassa verde no pólo de Jeremoabo - BA para estudos da desertificação. Relatório final sobre as atividades desenvolvidas como bolsista do FAPESB apresentado à coordenação do Programa Institucional de Bolsas de Iniciação Científica - FAPESB/UEFS. - UEFS, 2013

CASSETI, Valter. Elementos de geomorfologia. Goiania: Ed. UFG, 1994.

CHRISTOFOLETTI, A. Geomorfologia Fluvial. 2ª ed. São Paulo: Edgard Blücher, 1980.

CHRISTOFOLETTI, Antônio. Análise morfométrica de bacias hidrográficas. Notícia Geomorfológica, v. 9, n.18, p. 35-64, 1969. 